\title{
Research and Practice of Optics Teaching Mode Reform
}

\author{
Gui-Juan Yang ${ }^{1, a}$,Bin Wang ${ }^{1, b}$ and Xue-Lian Niu', c, \\ ${ }^{1}$ School of Science, Dalian Ocean University, Dalian 116023, China \\ aguijuanyang@dlou.edu.cn, bwangbinphy@dlou.edu.cn, ${ }^{\circ} 65360461 @ q q . c o m$
}

Keywords: Optical, Resources sharing, Teaching mode; Blending teaching; Innovation ability

\begin{abstract}
The article concerned resource sharing, integration and optimization the related optical courses, accommodation of knowledge cohesion between different courses using our teaching research results in recent years. Blending teaching was adopted to guide students to study by themselves and cultivate the innovation spirit and ability. Based on CDIO mode of practice teaching, that will cultivate students' innovation ability. At the same time, this article proposed the application of the research-based teaching mode to the optical course of advanced students comprehensive quality. To be enhanced optical course radiation efficiency, optical essential resource would be constructed by "points" to the "surface" to promote the construction of a large range of courses and improve level and quality of teaching.
\end{abstract}

\section{Introduction}

In accordance with ministry of education "about some ideas improving higher vocational education quality of teaching all round" and "Emancipating the mind strive to go beyond further promote the reform of basic physics teaching innovation initiative", we should renew the education ideas, deepen reform of optical class collaborative learning, emancipate the mind from time to time to cultivate optical essential resource sharing class.

\section{Integration and optimization of resource sharing about the related optical courses}

Optics is a course in utility strongly through the practice to deepen understanding of the theory. It is found problems in practice, which will promote learning and exploration of the theory. The theory and method of system theory was used to analyze and search of relationship between internal factors and external environment.

Optics courses are closely linked and share resources. Firstly, Teacher can share resources. Optical team members are from department of basic physics, department of special physics and teaching and teaching center of experimental physics, respectively. Therefore, teacher was teaching theory and teaching experiment, teaching specialized courses and public basic course teaching, could make full use of teaching resources. It made teachers arrange the teaching plan and students learn the most valuable new practical knowledge. Also it provided a unique basis for the formation and development of the teaching team. Secondly, the experiment equipment can also be shared for teachers and students including optical basis experiment and optical professional experiment. More and more advantages existed in playing out resource effectiveness of the function and saving money. Lastly, relevant teaching resources were sharing. In order to prevent unnecessary duplication of 
resources, optical boutique courses and optical video public class teaching resources (lesson plans, multimedia courseware and flash materials) were shared with unconditional using. That will be achieved more abundant quality optical teaching resources sharing, promoted the construction of other related courses, improved quality of teaching [1].

Optical content of course can be divided into three modules: theory, experiment module and expand module. According to our training plan, theoretical module mainly covered optics, college physics (including optics), optoelectronic technology, the photovoltaic materials and solar cells, which not only provided students with the basic conception of optical, basic principles, basic methods, also prepared for follow-up study and practice. Experiment module included physics experiment, basic physics experiment and modern physics experiment, which respectively trained the aspects of experimental skills. While expand module mainly included the design and application of physical experiment, method and technology of professional physical experiment. However, We built the bridge for optical theory and optical practice teaching to stimulate students' interests in optical related courses and train students' ability to find problems and solve practical problems.

In this paper, the theory of collaboration has been applied into the research, and has been organic integration and reasonable configuration for effective coordination of between optical courses cohesion, can complement each other. On the basis of knowledge of optical without repeat and omission, courses were explained from different perspectives, gradually deepening understanding of optical knowledge [2]. To be enhanced optical course radiation efficiency, optical essential resource would be constructed by "points" to the "surface" for promoting the construction of a large range of courses. The combination of tradition and modern, theory and experiment, basis and professional skills, we must speed up public basic courses construction to accelerate the pace of major curriculum.

\section{Stimulate students study enthusiasm using the method of blending teaching}

Based on the theory of educational psychology, following the theory of collaboration, accounting education reform with "research, exploratory, collaborative learning" concept of modern education. In combination with a variety of teaching methods, including blackboard writing, text, sound, graphics, the demonstration experiment, teaching video, video public class and micro-course, making teaching methods promoting each other. We made full use of the network teaching resources for auxiliary support, and stimulated students' study enthusiasm.

Optical part of college physics had tried out the method of the blending teaching by scanning the microcode in the second edition of the new basic physics or Liaoning online optical public course. The blending teaching is the new tendency of current international education technology development, which is combined with the advantages between face-to-face teaching and E-learning [3]. The method let the students from passive learning into active learning, the teaching model from style of teaching into inquiry. So, according to online optical public course, asked questions, find information before class, discuss and explore with the dorm, face to face communication in class, and review and solving puzzles. The blending teaching would let students build structure of knowledge, make teachers have more time to communicate with students [4]. 
Although the quantity of our video open courses is limited, we will carry on to construct them and expand the hybrid teaching for the purpose of providing students more space for their independent study [5]. With the objective of acquiring a high-class open course at the provincial level, guaranteeing the efficient employment of the courses and continuable development and improving the quality of teaching, we will proceed to pay out our great effort definitely to update, upgrade and research this product.

\section{CDIO mode of practice teaching to cultivate students' innovation ability}

Being the up-to-date achievement of reformation from international engineering education in recent years, CDIO is the international advanced idea for education and teaching, which represents Conceive, Design, Implement and Operate [6].

With the visual angle of CDIO, we try to reform teaching content and system settings, explore and practice the mode of personnel training and teaching in the interest of combining knowledge, ability and quality closely and uniting theory, practice and innovation [6]. Also in the practice, we attach importance to the basic, relax the caliber and emphasize innovation. For the sake of stimulating the students' interest in learning, developing their abilities in designing and using knowledge and practicing their ability of DIY, we organize some activities to improving the design of optical experiments and related experimental equipments, which strengthen the horizontal connections between courses and make their reasonable combination come true simultaneously. All these activities can inspire the students' desire of innovation, make them acquire new motivations and stimulate their innovative thinking in the process of acquiring knowledge. In order to cause the students' interest in learning and with the objective of changing the dull study to acquiring knowledge and hands-on learning, we introduce the optical history, the applications of optics in the life practice, the physicists and the experimental improvements, etc. Proceed from these activities students' learn how to innovate, dare to innovate and acquire the habit of innovation. And at the same time they enjoy the pleasure from the innovation.

Based on CDIO mode in experiment teaching, paying attention to cultivate students' innovative thinking and practical ability and combining with theme from the United Nations Educational, Scientific and Cultural Organization in 2015 (the international year of optics), students are required to design applicable devices, assemble experimental equipments and apply principle of interference (or diffraction) of light to optical experiments or actual measurements by way of improving the students' skill and ability in using optical methods and optical instruments. Under the guidance from teachers, students are divided to form the project team to acquire the practice of completing investigation, demonstrating, designing, selecting equipments and carrying out specific research. We are supported by the very dedicated teachers to launch the research learning. Our teachers are willing to guide the undergraduate to do these academic research and innovative experiments. Our teachers even give up their vacation or space time after work to open the lab for all students and provide the required laboratory consumables, experimental equipments and testing instruments to help the students as the teachers' ability allows. The students use their spare time to study. Research and study interact with each other simultaneously. The students' abilities in independent researching, 
exploring and solving physical problems are greatly improved. The students also benefit from these practice in improving their consciousness of innovation, innovative ability, practical ability and team cooperation consciousness.

The teachers in the optical team attach great importance in practice teaching and cultivating students' innovative ability. As the first guidance, they guide more than 200 students to participate in the extracurricular activities of science and technology receiving more than 40 awards. These awards include third prize and bronze respectively in "Challenge Cup" National College Students' Extracurricular Science and Technology Academic Competition, one gold award in "Challenge Cup" Liaoning province College Students' Extracurricular Science and Technology Academic Competition, 2 special awards in College Students' Entrepreneurship Program of Liaoning province, one first award in Physics Experiment Competition of Liaoning province, one first award in Dalian Creative Competition, 7 utility model patents ( 3 for student as the first inventor), 2 applications and 1 first award in College Students Innovation and Entrepreneurship Training Program, 3 teachers are named "Excellent Advisers" in College Student Extracurricular Academic Science and Technology Competition of Liaoning province.

\section{Research-based teaching mode and cultivating students' comprehensive quality}

The research-based teaching mode is used in optics teaching and the five processes of this teaching mode is employed in the class to implement the research. (1) Preparation: paying importance in key and difficult points, the teacher explains the teaching material to students briefly and introduces some related papers, on-line data and practical applications [7]. (2) Determination of the research subject: in accordance with the teaching content the teacher provides different research subjects. The project can be represented in the form of courseware making, paper writing, software development and modification, designing or production of equipments. Every student are required to participate in one or two research group to design their own research subject. (3) Formulation of research plan: a member from the group reports their research plan which is examined and questioned by the teacher and members from other groups. The teacher reviews and explains the details of the key points in the curriculum. All these activities can deepen the students' understanding of key points, improve their abilities in finding, analyzing and solving problems and cultivate the students' teamwork spirit [8]. (4) Implementation of the research: according to the research subject and plan, the students carry out research gradually. The teacher plays an important role when the students meet some difficulties in guiding, hinting and helping them to find and solve problems. (5) Exhibition evaluation of achievements: reporting, exhibiting and evaluating are performed after the completion of the subject. Outstanding achievements are detailed analyzed and are taken precedence to be submitted to a variety of innovative entrepreneurship competitions, patent applying and publishing.

Research-based teaching mode is an interactive teaching process fully embodied with students as the center, projects as the carrier, teams as the unit and research as the direction. The research-based study employed in optics teaching, makes teachers change their role from communicators of knowledge to the supervisor of knowledge constructing and makes students also 
turn their position from passive recipients to the active builders of knowledge. In the aspect of cultivating the students' cooperation spirit, research-based teaching mode is not only the process of training students' abilities in analyzing and solving problems but also the one to cultivate the students' comprehensive abilities of communication, cooperation and coordination. The exploration of implementing research-based study in optics teaching makes the research-based study and classroom teaching benefit a lot from each other.

\section{"Mentoring" improving the quality of teachers}

The teacher is the most key factor for the colleges and universities to achieve their viewpoints and ideas of education. The overall quality and professional level of teachers have a strong connection with reform and development of education. The teaching quality of universities is decided by the level of teachers while the latter depends not only on their own efforts and strength, but also on the effective communication among the teachers. The capability of extending or connecting one course with other courses and knowledge from frontier of this subject, requires the teacher acquiring a wide range of professional knowledge together with the modern teaching philosophy.

We uphold these principle: combination of three generations; carrying forward the tradition "mentoring"; linking theory with practice (the teacher undertakes both theory teaching and experimental guiding); combining public basic courses and professional ones (the teacher undertakes both basic and professional teaching). With other teachers' review and guide, young teachers carry out public class. Playing an exemplary role in young teachers' training, professors give model lessons and invite the young teachers to inspect and learn with the purpose of making them have a healthy and rapid growth in teaching. Our recent achievements include one first award in the Third Young Teachers Teaching Skill Competition, one second award in the Fourth Young Teachers Teaching Skill Competition, one excellent award in 2015 New Teachers Test of Basic Teaching Skill, two teachers receiving honorary tiles of "Blue Talent" and "Azure Blue Talent" respectively, one teacher being rated as "Teaching model" and "the Most Beautiful Teacher" of Dalian Ocean University.

\section{Acknowledgements}

This work was financially supported by Research Project on the Reform of Teaching Mode of Undergraduate Education in Universities of Liaoning province (UPRP20140494) and 2014 Key Project of Education and Teaching Reform of Dalian Ocean University (JG2014ZD23).

\section{Reference}

[1]H.B. Chen, J.T. Zhang, Y.Z. Liu and J.Z Zhao: Journal of Shanxi Agricultural University (social science edition), 2011,10(2).

[2] L.L. Zhao: Journal of Chifeng Institute (natural science edition), 2012, 28 (4).

[3] F. Lu: Teaching of University Teaching in China, 2014, (1). 
[4] J. Wen, X.Y. Li, A.H. Mei and Y.X. Zhang:The People's Liberation Army Hospital Management Journal, 2014, 21 (9).

[5] X. Zhong, A.P. Xiang,J.Y. Hou, F. Chen and L. Luo: Journal of Chengdu Information Engineering College, 2009, 24 (6).

[6] J. He, F. Qi, J. Jie, N. Ye and F. Tian: Computer Knowledge and Technology, 2015, 11 (2).

[7] N. Xu: Exploration and Practice of Electrical and Electronics Teaching Science, 2012 (3).

[8] J. Zhang and X.J. Fu: University Teaching in China, 2007, (12). 